\title{
The Oriented Attachment Model Applied on Crystal Growth of Hydrothermal Derived Magnetite Nanoparticles
}

\author{
Ahmad Fadli ${ }^{1, *}$, Amun Amri ${ }^{1}$, Iwantono ${ }^{2}$, Arisman Adnan ${ }^{3}$, Sunarno $^{1}$, Sukoco $^{1}$, and Mayangsari ${ }^{1}$ \\ ${ }^{1}$ Department of Chemical Engineering, Faculty of Engineering, Universitas Riau, \\ Kampus Binawidya, Jl. HR. Soebrantas Km. 12.5, Simpang Baru, Panam Pekanbaru, Riau 28293, Indonesia \\ ${ }^{2}$ Department of Physics, Faculty of Mathematics and Natural Sciences, Universitas Riau, \\ Kampus Binawidya, Jl. HR. Soebrantas Km. 12.5, Simpang Baru, Panam Pekanbaru, Riau 28293, Indonesia \\ ${ }^{3}$ Department of Mathematics, Faculty of Mathematics and Natural Sciences, Universitas Riau, \\ Kampus Binawidya, Jl. HR. Soebrantas Km. 12.5, Simpang Baru, Panam Pekanbaru, Riau 28293, Indonesia
}

\author{
${ }^{*}$ Corresponding author: \\ tel: +62-761-588156 \\ email:fadliunri@yahoo.com \\ Received: January 22, 2019 \\ Accepted: May 9, 2019 \\ DOI: $10.22146 /$ ijc. 42917
}

\begin{abstract}
Magnetite $\left(\mathrm{Fe}_{3} \mathrm{O}_{4}\right)$ nanoparticles are very promising to be applied as a drug delivery system (DDS) for cancer chemotherapy. In this research, the crystal growth of hydrothermal derived magnetite particles was studied by oriented attachment (OA) model. The OA model was used to investigate the mechanism and the statistical kinetic of crystal growth. The crystal diameter change as a function of time with different concentration was measured using XRD. Firstly, $0.3248 \mathrm{~g} \mathrm{FeCl}_{3}$ and $1.1764 \mathrm{~g}$ of sodium citrate, as well as $0.3604 \mathrm{~g}$ urea were dissolved into $40 \mathrm{~mL}$ of distilled water in a reactor. Subsequently, the reactor temperature was maintained at $210{ }^{\circ} \mathrm{C}$ and the reaction time of 3.5-12 $\mathrm{h}$ in an air oven. The morphology of obtained particles was characterized using TEM, whereas VSM was used to determine the magnetic hysteresis curve. The XRD pattern showed that magnetite was obtained at temperature $210{ }^{\circ} \mathrm{C}$ and $3.5 \mathrm{~h}$ reaction time, as well as its intensity, increased with reaction time. The crystal size of $\mathrm{Fe}_{3} \mathrm{O}_{4}$ was $9.44 \mathrm{~nm}$ at $3.5 \mathrm{~h}$ and was appropriate with the oriented attachment model. The magnetite nanoparticles with shaped core-shell had a size less than $50 \mathrm{~nm}$ and were suitable for biomedical application, especially as drug delivery.
\end{abstract}

Keywords: magnetite; oriented attachment; crystal growth; hydrothermal; nanoparticles

\section{- INTRODUCTION}

Nanomagnetite particles have been widely used in electronics, industry, biomedicine, and agriculture. In the electronics field, nanomagnetite has been applied as magnetic storage media, ferrofluids, sensors, supercapacitors, and data memory, whereas application of nanomagnetite in industries such as ceramics, catalyst, and energy storage. In the medical field, nanomagnetite has been used as magnetite resonance imaging (MRI) contrast media and drug delivery system (DDS) for cancer chemotherapy [1]. Cancer is one of the leading causes of death worldwide. Compared to conventional methods such as oral and injection, DDS has the ability to treat specific targets in the body, reduce drug doses, reduce drug concentration on non-target site and reduce the side effects caused by drug toxicity on non-target cells or tissues [2]. Nanomagnetite which can be applied as DDS has been carried out in many nanomagnetite synthesis studies, but there is no modeling that explains the tailoring process of nanomagnetite particles. Modeling is used to determine the evolution and factors that influence the growth of nanomagnetite crystals to obtain uniform size and morphology [3].

Two models can explain the growth of nanomagnetite particles, Ostwald Ripening (OR) and Oriented Attachments (OA). The OR model is a classic model that explains the growth of increasing nanomagnetite crystals through diffusion. This model has not been able to explain the limits of the enlargement

Ahmad Fadli et al. 


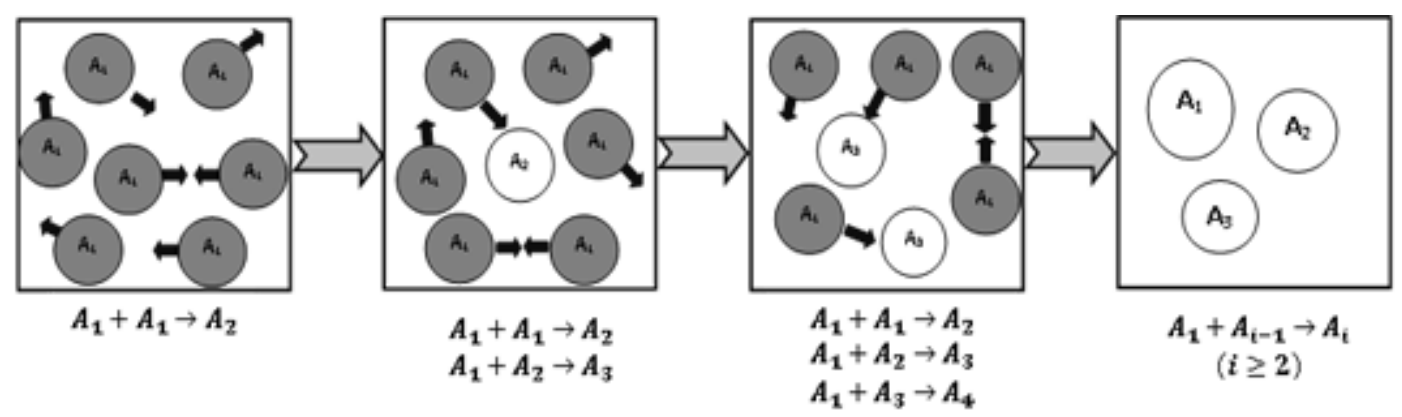

Fig 1. Schematic illustration of nanomagnetite crystal growth by Oriented Attachment $(\mathrm{OA})$ model

of the nanomagnetite crystal particles. The OA model will explain more about the particle union, the factors that influence and the particle size limits so that the crystal diameter size of the nanomagnetite particles is uniform [4]. Model OA describes crystal growth based on the joining of crystalline particles. The primary particle meets the other primary particles to form secondary particles. Secondary particles meet with primary particles forming tertiary particles and so on. Illustration of nanomagnetite crystal growth scheme with the OA model can be described as Fig. 1. Primary particles A1 meet with the other primary particles $A_{1}\left(A_{1}+A_{1}\right)$ grow into secondary particles $\left(A_{2}\right)$, then the union between the primary particles and multiple particles occurs $\left(A_{1}+A_{2}\right),\left(A_{1}+A_{3}\right)$ and so on. The hypothesis stated by Zang et al. [5], the meeting between $A i$ and $A_{j}$ for $A_{i} \geq 2$ and $A_{j} \geq 2$ is limited by assuming that the particle mass is uniform, if $A_{j} \geq 2$ then the particle mass is too large, immobility and opportunities for small interactions and reaction growth of nanomagnetite crystal are irreversible reactions. The kinetic model of $\mathrm{OA}$ is described by the following reactions:

$\mathrm{A}_{1}+\mathrm{A}_{1} \stackrel{\mathrm{k}_{1}}{\longrightarrow} \mathrm{A}_{2}$

where $A_{1}$ is the primary nanomagnetite particles, $A_{2}$ is the product of two united nanomagnetite particles and $k_{1}$ is the kinetic constant of the reaction between two particles. Primary nanomagnetite particles that combine with other primary particle products and so on (multiple particles) can be illustrated by the following reactions:

$\mathrm{A}_{1}+\mathrm{A}_{\mathrm{i}-1} \stackrel{\mathrm{k}_{\mathrm{i}-1}}{\longrightarrow} \mathrm{A}_{\mathrm{i}}$

where $A_{i}$ is a particle containing i primary and $k_{i}$ is the reaction rate constant.

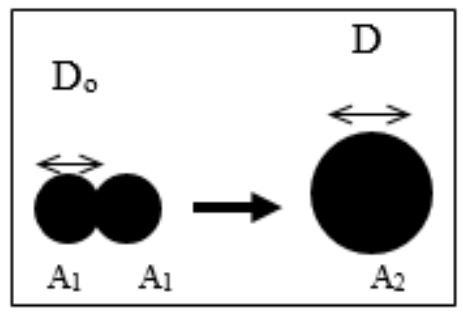

Fig 2. Illustration of growth of a nanomagnetite crystal in the OA model

It is assumed the particle with an average diameter of $\mathrm{D}_{0}$ and the particle volume units $\mathrm{N}_{0}$ at $\mathrm{t}=0$. After the particles have grown at a time period, $t$, the number of particles is $\mathrm{N}(\mathrm{t})$, and the number of particles that have grown is $\mathrm{N}_{2}(\mathrm{t})$, and the average particle size is $\mathrm{D}_{2}$. Assumed that the particles are spherical, the balance equation at $\mathrm{t}$ time is:

$\frac{4}{3} \pi\left(\frac{\mathrm{D}_{0}}{2}\right)^{3} \mathrm{~N}_{0} \rho=\frac{4}{3} \pi\left(\frac{\mathrm{D}_{0}}{2}\right)^{3} \mathrm{~N}_{(\mathrm{t})} \rho+\frac{4}{3} \pi\left(\frac{\mathrm{D}_{2}}{2}\right)^{3} \mathrm{~N}_{2(\mathrm{t})} \rho$

where $\rho$ is the nanomagnetite particle density. This equation can be changed to:

$\frac{1}{6} \pi\left(D_{0}\right)^{3} \mathrm{~N}_{0} \rho=\frac{1}{6} \pi\left(\mathrm{D}_{0}\right)^{3} \mathrm{~N}_{(\mathrm{t})} \rho+\frac{1}{6} \pi\left(\mathrm{D}_{2}\right)^{3} \mathrm{~N}_{2(\mathrm{t})} \rho$

where $\mathrm{V}_{2}=2 \mathrm{~V}_{0}$, then:

$\mathrm{D}_{2}=\sqrt[3]{2 \mathrm{D}_{0}}$

According to Huang et al. [6], because the amount of particle growth is the number of particles per unit volume at $(\mathrm{t})$ then:

$\mathrm{N}_{2(\mathrm{t})}=\frac{\mathrm{N}_{0}-\mathrm{N}_{(\mathrm{t})}}{2}$

The kinetics integration of nanomagnetite particle growth can be explained in the equation:

$\mathrm{N}_{(\mathrm{t})}=\frac{\mathrm{N}_{0}}{\mathrm{kt}+1}$ 
Huang et al. [6], used the Scherer method with XRD, the diameter of each particle is declared with the equation: $\mathrm{D}=\mathrm{N}(\mathrm{t}) \cdot \mathrm{D}_{0}+\mathrm{N}_{2}(\mathrm{t}) \cdot \mathrm{D}_{2}$

If Eq. (5), (6) and ((7) is combined with the Eq. (8), then obtained:

$$
\mathrm{D}=\frac{\mathrm{D}_{0}(\sqrt[3]{2 \mathrm{kt}}+1)}{(\mathrm{kt}+1)}
$$

The nanomagnetic synthesis was successfully carried out by Cheng et al. [4] used $\mathrm{FeCl}_{3}$, citrate, urea, and polyacrylamide (PAM) by the hydrothermal method at temperature $200{ }^{\circ} \mathrm{C}$. The nanomagnetite particles obtained are hollow and core shell. These particles have nanoparticle size and morphology that affect accessibility and residence time in blood circulation, superparamagnetic, high solubility in water and ideal for application as DDS [7].

In this study, the application of the OA model on the growth of nanomagnetite synthesis crystal in the hydrothermal method is carried out. Therefore, the nanomagnetite from the synthesis will be maximal and uniform that can be applied to the DDS.

\section{- EXPERIMENTAL SECTION}

\section{Materials}

The materials used were $\mathrm{FeCl}_{3} \cdot 6 \mathrm{H}_{2} \mathrm{O}$ (Nacalai Tesque), urea (Merck), $\left(\mathrm{C}_{6} \mathrm{H}_{5} \mathrm{O}_{7} \mathrm{Na}_{3} \cdot 2 \mathrm{H}_{2} \mathrm{O}\right)$ (Merck), polyethylene glycol (PEG) 1000 (99\%), aquabidest and ethanol (Merck).

\section{Instrumentation}

The crystallinity, composition, and size of nanoparticles were determined by XRD analysis, with $\mathrm{Cu}$ radiation lamps ( $\lambda 1.54 \AA$, $40 \mathrm{kV}$ and $30 \mathrm{~mA}$ ). The DebyeScherrer method was used to calculate the particle size by using Eq. (10).

$\mathrm{D}=\frac{\mathrm{K} \lambda}{\mathrm{B} \operatorname{Cos} \theta}$

Morphology, topography, composition, and crystallographic information of samples were analyzed using Transmission Electron Microscope (TEM). Nanoparticle magnetism was analyzed by Vibrating Sample Magnetometer (VSM) VSM 1.2H Oxford type.

\section{Procedure}

\section{Nanomagnetite synthesis using a hydrothermal method}

Nanomagnetite synthesis used the hydrothermal method that has been carried out by Cheng et al. [4] with modification. $0.3248 \mathrm{~g} \mathrm{FeCl}_{3} \cdot 6 \mathrm{H}_{2} \mathrm{O}, 1.1764 \mathrm{~g}$ sodium citrate, and $0.3604 \mathrm{~g}$ urea were dissolved in $40 \mathrm{~mL}$ distilled water, the $0.1 \mathrm{~g}$ of PEG was added while stirring until it dissolved completely, then it put in a Teflon reactor. The reactor was put into the oven and set at $210{ }^{\circ} \mathrm{C}$. The reaction time used in this study was $3.5,5$, 7,9 , and $12 \mathrm{~h}$. The black precipitate that was formed then carried out with the help of an external magnetic field so that the process could be carried out quickly and more effectively. Washing the sediment with an aqueous solution, repeat it several time to obtain pure $\mathrm{Fe}_{3} \mathrm{O}_{4}$ sample. The sample was then dried in an oven for $12 \mathrm{~h}$ at $60{ }^{\circ} \mathrm{C}$. The dried precipitate was then weighed and determined by the yield percentage by comparing the weight of precipitate to the theoretical $\mathrm{Fe}_{3} \mathrm{O}_{4}$ weight obtained from the stoichiometric equation.

\section{Nanomagnetite crystal growth model}

From the experimental data obtained, the diameter of nanomagnetite crystal plotted with the synthesis time to obtain curve graphs. The curve obtained from the experiment was matched with the model curve of oriented attachment $(\mathrm{OA})$.

\section{- RESULTS AND DISCUSSION}

\section{Nanomagnetite Synthesis}

Nanomagnetite synthesis by the hydrothermal method was carried out by mixing a precursor with a reducer and water in an autoclave at high temperature for 3.5-12 h. Nanomagnetite is formed by the reaction between the molecules of $\mathrm{Fe}(\mathrm{II})$ hydroxide with 2 molecules of $\mathrm{Fe}$ (III) hydroxide [8], with the following reactions:

$\mathrm{Fe}(\mathrm{OH})_{2(\mathrm{~s})}+2 \mathrm{Fe}(\mathrm{OH})_{3(\mathrm{~s})} \rightarrow \mathrm{Fe}_{3} \mathrm{O}_{4(\mathrm{~s})}+4 \mathrm{H}_{2} \mathrm{O}_{\mathrm{aq}}$

Stoichiometrically, nanomagnetite crystals were formed from $\mathrm{Fe}^{3+}$ and $\mathrm{Fe}^{2+}$ with a 2:1 ratio [9]. Citrate addition acts not only as a reducing agent but also plays an important role in the formation of crystal morphology 
and aggregation prevention.

PEG functions as a capping agent and as a substance that can form and control the pore size and structure. PEG can dissolve in water, methanol, benzene, and dichloromethane, besides PEG also has a low toxic content. PEG has an -OH group on the surface of the nanoparticles making the nanoparticles hydrophilic and negatively charged, it makes the nanoparticles have a longer residence time in the bloodstream (high bioavailability) because they correspond to the nature of plasma proteins which are also hydrophilic and negatively charged. Phagocytosis will occur in non-polar (hydrophobic) particles and positively charged [10].

The nanomagnetite formed was characterized by black precipitate that can interact with magnetic fields. At temperature $210^{\circ} \mathrm{C}$, the concentration $0.05 \mathrm{M}, 3.5 \mathrm{~h}$ of synthesis the precipitate began to form. Precipitate dispersed in water can interact and were attracted to the magnet. Products of nanomagnetite synthesis at reaction times of 3.5, 5, 7, 9 and $12 \mathrm{~h}$ have a blackish brown in the form of fine powder that can interact with external magnets. Visually the synthesized product at a reaction time of 3.5, 5, 7, 9, and $12 \mathrm{~h}$ would see a change of color from brownish yellow and will be darker.

\section{Nanomagnetite Properties}

Based on the diffractogram form of XRD analysis, it was identified that precipitate at $210^{\circ} \mathrm{C}$ and a reaction time of $3.5 \mathrm{~h}$ had formed nanomagnetite, and the intensity would increase with increasing synthesis time. In Fig. 3, it can be seen that the diffractogram pattern for each synthesis has the same pattern as the ICSD standard diffractogram No. 01-076-7168 and the highest intensity at $2 \theta$ of $35.54,57.0564$, and $62.66^{\circ}$. It also can be seen that nanoparticles consist of the pure compound, without the presence of other iron oxide compounds or the reactants used in the synthesis process. This indicates that the hydrothermal method carried out in this experiment has good performance and selectivity in synthesizing one type of nanoparticles.

Mass produced (yield) the products will increase with increasing the synthesis time, at 3.5, 5, 7 and $9 \mathrm{~h}$ of synthesis time the yield was $39.18,71.84,78.37,98.6 \%$ and

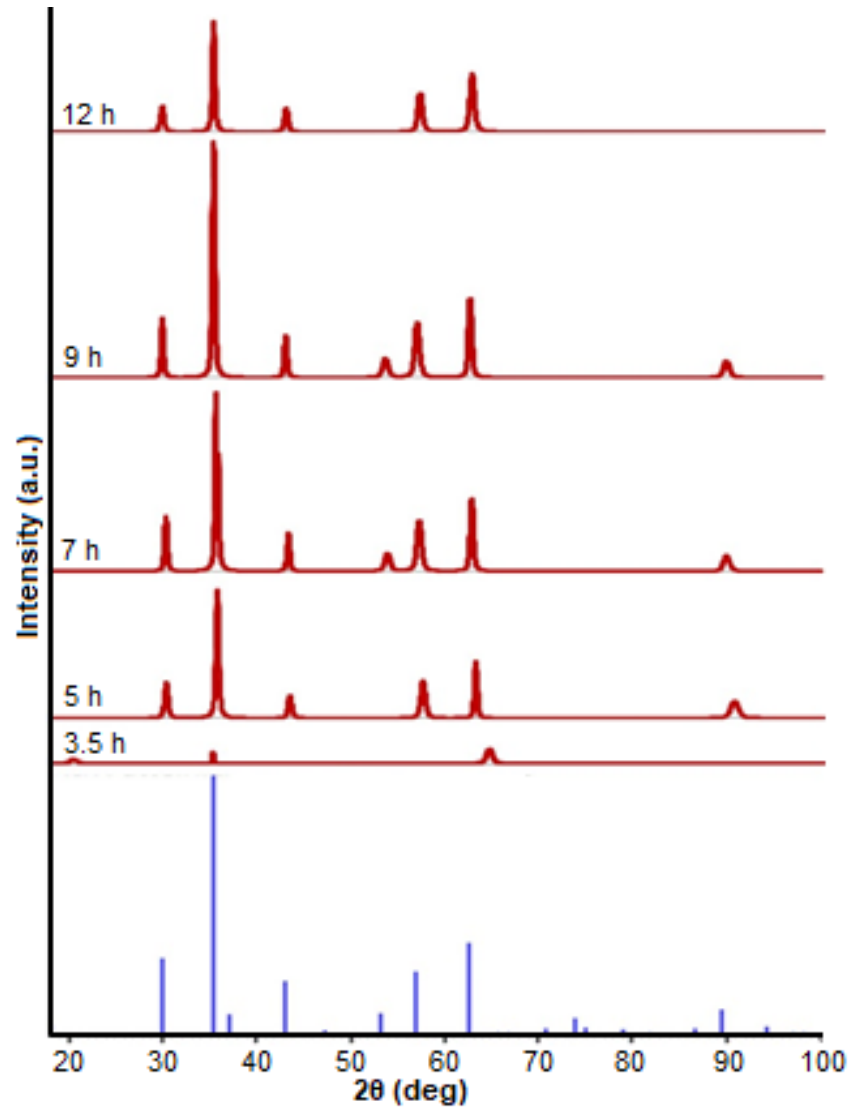

Fig 3. XRD diffractogram of nanomagnetite at 3.5, 5, 7, 9 and $12 \mathrm{~h}$, temperature of $210^{\circ} \mathrm{C}$ and concentration of $0.05 \mathrm{M}$

Table 1. Nanomagnetite crystal diameter at different synthesis time

\begin{tabular}{cc}
\hline Synthesis time $(\mathrm{h})$ & Nanomagnetite crystal diameter $(\mathrm{nm})$ \\
\hline 3.5 & 9.44 \\
5 & 12.82 \\
7 & 16.71 \\
9 & 20.31 \\
12 & 27.50 \\
\hline
\end{tabular}

then decreased slightly after $12 \mathrm{~h}$ of synthesis, which was only $97.96 \%$.

Using the Scherrer's equation, the crystal diameter of obtained magnetite at $3.5,5,7,9$, and $12 \mathrm{~h}$ were 9.44 , $12.82,16.71,20.71$, and $27.50 \mathrm{~nm}$ respectively.

To find out the magnetic properties, characterization was carried out using the vibrating sample magnetometer (VSM) method at $300 \mathrm{~K}$ with the application of an external magnetic field in the range of 
$-1 \mathrm{~T}$ to $1 \mathrm{~T}$. Fig. 4 shows a hysteresis curve of nanomagnetite synthesized at $210{ }^{\circ} \mathrm{C}$ for $12 \mathrm{~h}$ with characteristic curves in the form of a symmetrical return sequence and a narrow curve. Based on the hysteresis loop curve, the saturation magnetic (Ms), coercivity field (Hc) and remnant magnetization ( $\mathrm{Mr}$ ) can be determined. The saturation magnetization value, also known as saturated magnetization, shows the ability of nanomagnetite particles to maintain the alignment of their magnetic domains when there are external magnets. The coercivity field is the amount of field needed to make the magnetization zero. The higher the coercivity field value, the stronger the magnetic properties of the material was. Meanwhile, the remnant magnetic shows the magnitude of the remaining magnetic field.

Narrow hysteresis loop shows small energy loss and ease of magnetization. This makes magnetite synthesis not only good to be applied as drug delivery but also very promising as recording media, data storage, and supercapacitor media. Nanomagnetite particles were soft magnetic; it can be seen from the hysteresis curve that has a symmetrical return sequence when there was a magnetic field. Soft magnetite needs very small energy for magnetization process. The superparamagnetic properties of magnetite are due to the electron transfer between $\mathrm{Fe}^{3+}$ and $\mathrm{Fe}^{2+}$ in octahedral lattice [11] and the presence of an unbalanced antiparallel spin pair on the crystal lattice [12]. Size is also an important factor that determines the paramagnetic properties. Nanomagnetite particles with a diameter of less than $30 \mathrm{~nm}$ and paramagnetic properties are obtained $[4,12]$.

The diameter of nanomagnetite particles is related to their magnetic properties. At room temperature, a particle with a size of $5 \mathrm{~nm}$ is superparamagnetite without interaction between particles, $19 \mathrm{~nm}$ is ferrimagnetite and
$11 \mathrm{~nm}$ iron oxide nanoparticles are superparamagnetite with several interactions between particles [13]. The saturation magnetization (Ms) is perpendicular to the degree of crystallinity of the nanoparticles. The increase of particle crystallinity also increases the saturation magnetization [14]. Due to the high crystallinity, nanomagnetite structure is almost close to the crystal structure of bulk material [15]. At synthesis time of $12 \mathrm{~h}$ with $0.05 \mathrm{M}$ concentration, the Ms of nanomagnetite was $81(\mathrm{Emu} / \mathrm{g})$. The decrease in crystal diameter increased the susceptibility to the magnet because of the formation of a single electron spin domain [16-17]. The value of nanomagnetite saturation magnetization is smaller than the bulk material due to incomplete coordination between atoms on the surface and the presence of superexchange (SE) interactions between $\mathrm{Fe}$ ions connected by $\mathrm{O}^{2-}$ ions which cause the spin disorder on the particle surface [18].

Morphology characterization of nanoparticles was analyzed using JEM-1400 with TEM image. Based on

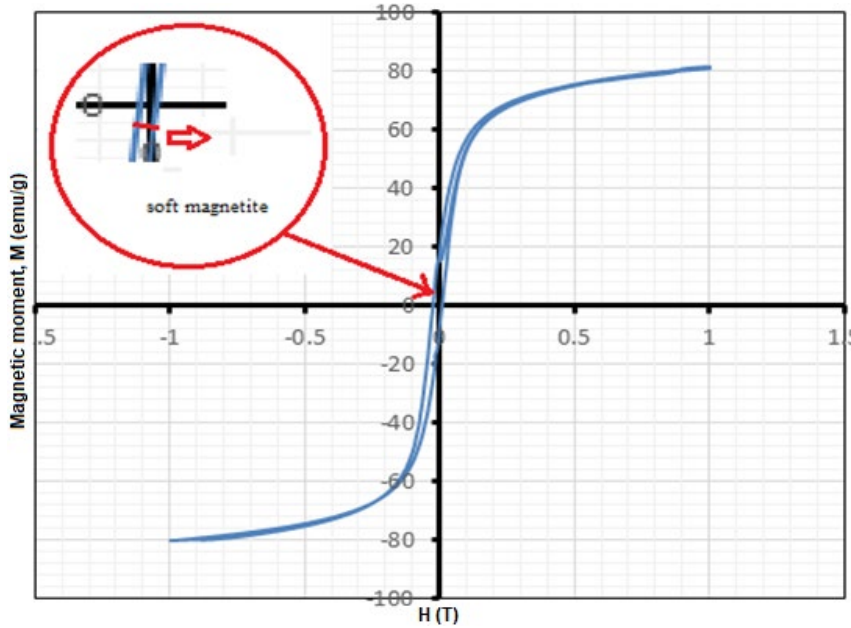

Fig 4. Magnetite loop hysteresis curve at the synthesis of $12 \mathrm{~h} 210^{\circ} \mathrm{C}$ concentration of $0.05 \mathrm{M}$
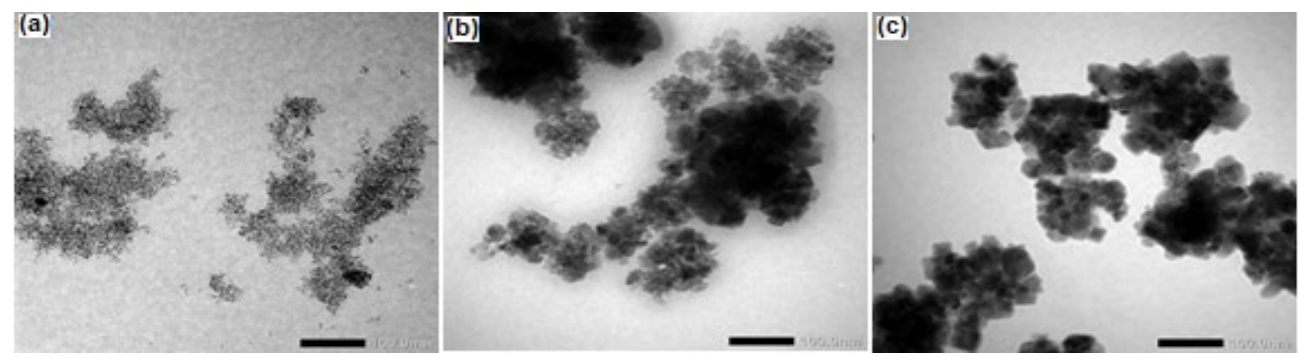

Fig 5. TEM images of synthesized samples at the time of (a) $3.5 \mathrm{~h}$, (b) $5 \mathrm{~h}$, and (c) $12 \mathrm{~h}$ 
TEM images at 80,000 times magnification, the crystal morphology of nanomagnetite can be seen. Nanoparticles with $3.5 \mathrm{~h}$ of synthesis time were seen in TEM images as black and dark crystal.

At synthesis time of $3.5 \mathrm{~h}$, it was generally seen that the particles formed were nano-sized with uniform size distribution and no agglomeration. Nanoparticles were spherical-form with a diameter of about $20 \mathrm{~nm}$. Whereas the nanomagnetite synthesized with $7 \mathrm{~h}$ of synthesis time, the shape was close to the core-shell shape with a dark core and brighter part of the shell with a diameter less than $50 \mathrm{~nm}$. At the synthesis time of $12 \mathrm{~h}$, a perfect formation of nanomagnetite was formed with dense coreshell and diameter about $100 \mathrm{~nm}$. This core-shell structure consists of small particles with a size of about 20 $\mathrm{nm}$, which were agglomerated with high crystallinity in the core and amorphous in the shell.

\section{Nanomagnetite Crystal Growth by Oriented Attachment (OA) Model}

Based on experimental data obtained from XRD, the $\mathrm{k}$ value obtained from the concentration of $0.05 \mathrm{M}$ with various reaction times is shown in Fig. 6. From the value of $\mathrm{k}$, the diameter of the model was determined by substituting $\mathrm{D}_{0}$ and $t$ parameters, so the diameter of the model for certain time was obtained. Nanomagnetite crystal diameter from the calculation of the $0.05 \mathrm{M}$ reactant concentration has a $\mathrm{k}$ value of -2.18 . From the value of $k$, the diameter of nanomagnetite crystal could be calculated used the OA model.

The diameter of the model is still close to the experimental results with a small percent error, as seen in Fig. 7. At a temperature of $210{ }^{\circ} \mathrm{C}$, the diameter of the model (D) for 3.5, 5, 7, 9, and $12 \mathrm{~h}$ of the reaction was 9.44, $11.69,16.05,20.41$, and $26.72 \mathrm{~nm}$, respectively whereas the experimental results of the particle diameter were $9.44,12.82,16.71,20.31$, and $27.50 \mathrm{~nm}$.

The crystal diameter of the experimental and calculation results in the increase of reaction time will approach the model point where the elevation point will decrease from the reaction time of $5,7,9$, and $12 \mathrm{~h}$. The diameter of the model calculation approximates the experimental results with small percent errors. At $5 \mathrm{~h}$ of

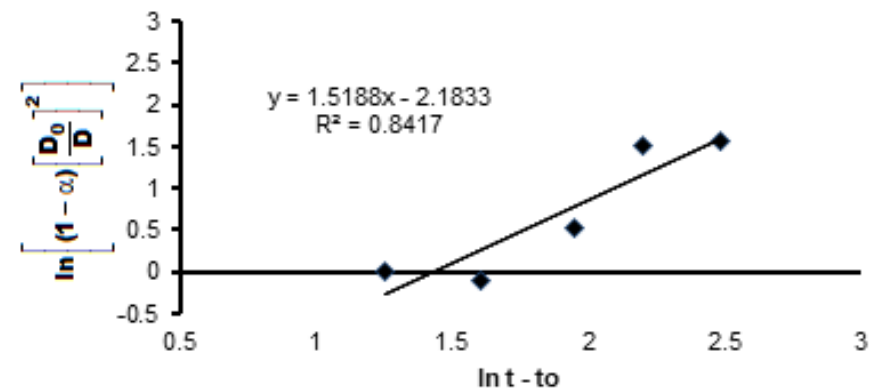

Fig 6. Graph value of $k$ at $0.05 \mathrm{M} 210^{\circ} \mathrm{C}$

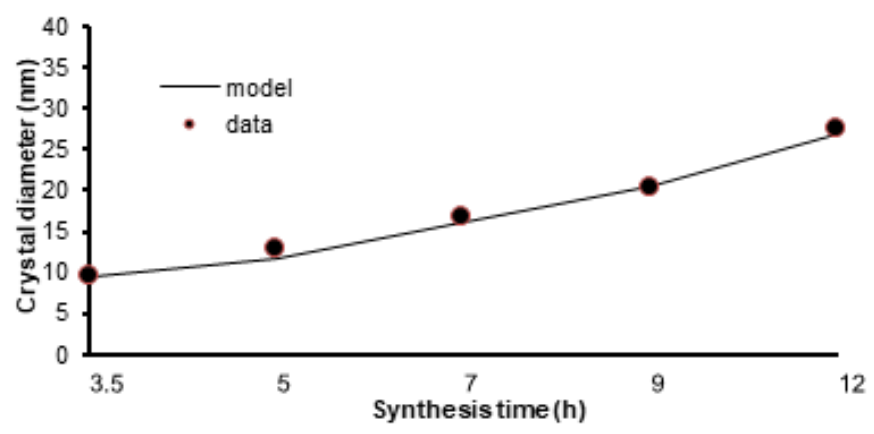

Fig 7. Diameter of magnetite crystal particle from experiment and modeling result

reaction time and $0.05 \mathrm{M}$ concentration, the percentage error obtained was $9.6 \%$. The increasing of reaction time, the growth of magnetite crystals will be more perfect with increasing reaction time and modeling of Oriented Attachment (OA).

\section{- CONCLUSION}

Nanomagnetite can be synthesized using a hydrothermal method with a synthesis time of 3.5, 5, 7, 9 , and $12 \mathrm{~h}$ at $210^{\circ} \mathrm{C}$. The reaction time affects the growth of magnetite crystal. The crystal diameter magnetite increases from 9.44 to $27.50 \mathrm{~nm}$ with increasing synthesis time from 3.5 to $12 \mathrm{~h}$. The morphology of nanomagnetite is core-shell shape without agglomeration with size particles approximately $100 \mathrm{~nm}$. The saturation magnetization (Ms) of nanomagnetite at $12 \mathrm{~h}$ synthesis time is $81(\mathrm{Emu} / \mathrm{g})$ with superparamagnetic properties, showing that the obtained nanomagnetite is suitable for drug delivery system (DDS) application. Model of Oriented Attachment $(\mathrm{OA})$ is appropriate for crystal growth of the magnetite with $k$ value of -2.18 . 


\section{- ACKNOWLEDGMENTS}

The authors are grateful for the financial support from Ministry of Research, Technology and Higher Education of Indonesia for the financing of this research with Contract Number 086/SP2H/LT/DRPM/2018.

\section{- REFERENCES}

[1] Hung, L.H., and Lee, A.P., 2007, Microfluidic devices for the synthesis of nanoparticles and biomaterials, $J$. Med. Biol. Eng., 27 (1), 1-6.

[2] Arruebo, M., Fernández-Pacheco, R., Ibarra, M.R., and Santamaría, J., 2007, Magnetics nanoparticles for drug delivery, Nano Today, 2 (3), 22-32.

[3] Chomoucka, J., Drbohlavova, J., Huska, D., Adam, V., Kizek, R., and Hubalek, J., 2010, Magnetic nanoparticles and targeted drug delivering, Pharmacol. Res., 62 (2), 144-149.

[4] Cheng, W., Tang, K., Qi, Y., Sheng, J., and Liu, Z., 2010, One-step synthesis of superparamagnetic monodisperse porous $\mathrm{Fe}_{3} \mathrm{O}_{4}$ hollow, J. Mater. Chem., 20 (9), 1799-1805.

[5] Zhang, J., Huang, F., and Lin, Z., 2010, Progress of nanocrystalline growth kinetics based on oriented attachment, Nanoscale, 2 (1), 18-34.

[6] Huang, F., Zhang, H., and Banfield, F.J., 2003, Twostage crystal-growth kinetics observed during hydrothermal coarsening of nanocrystalline $\mathrm{ZnS}$, Nano Lett., 3 (3), 373-378.

[7] Bae, Y.H., and Park, K., 2011, Targeted drug delivery to tumors, myths, reality and possibility, J. Phys. D: Appl. Phys., 153 (3), 198-205.

[8] Tartaj, P., Morales, M.P., Veintemillas-Verdaguer, S., González-Carreño, T., and Serna, C.J., 2003, The preparation of magnetic nanoparticles for applications in biomedicine, J. Phys. D: Appl. Phys., 36 (13), 182-197.

[9] Mohapatra, M., and Anand, S., 2010, Synthesis and applications of nano-structured iron oxides/hydroxides - A review, J. Eng. Sci. Technol., 2 (8), 127-146.

[10] Cao, X., Zhang, B., Zhao, F., and Feng L., 2012, Synthesis and properties of MPEG-coated superparamagnetic magnetite nanoparticles, J. Nanomater., 2012, 607296.

[11] Zhang, H., and Banfield, J.F., 1999, New kinetic model for the nanocrystalline anatase-to-rutile transformation revealing rate dependence on number of particles, Am. Mineral., 84 (4), 528-535.

[12] Hwang, N.M., Jung, J.S., and Lee, D.K., 2012, "Thermodynamics and kinetics in the synthesis of monodisperse nanoparticles" in ThermodynamicsFundamentals and Its Application in Science, Eds. Morales-Rodriguez, M., InTech, 371-388.

[13] Hyeon, T., Lee, S., Park, J., Chung, Y., and Na, H.B., 2001, Synthesis of highly crystalline and monodisperse maghemite nanocrystallites without a size-selection process, J. Am. Chem. Soc., 123 (51), 12798-12801.

[14] Lu, A., Salabas, E.L., and Schuth, F., 2007, Magnetic nanoparticles: Synthesis, protection, functionalization, and application, Angew. Chem. Int. Ed., 46 (8), 222-244.

[15] Chen, B.A., Mao, P., Cheng, J., Gao, F., Xia, G.H., $\mathrm{Xu}$, W.L., Shen, H.L., Ding, J.H., Gao, C., Sun, Q., Chen, W.J., Chen, N.N., Liu, L.J., Li, X.M., and Wang, X.M., 2010, Reversal of multidrug resistance by magnetic $\mathrm{Fe}_{3} \mathrm{O}_{4}$ nanoparticle copolymerizating daunorubicin and MDR1 shRNA expression vector in leukemia cells, Int. J. Nanomed., 5, 437-444.

[16] Gustafson, H.H., Holt-Casper, D., Grainger, D.W., and Ghandehari, H., 2015, Nanoparticle uptake: The phagocyte problem, Nano Today, 10 (4), 487510.

[17] Sabyrov, K., Burrows, N.D., and Penn, R.L., 2013, Size-dependent anatase to rutile phase transformation and particle growth, Chem. Mater., 25 (8), 1408-1415.

[18] Coulter, J.A., Jain, S., Butterworth, K.T., Taggart, L.E., Dickson, G.R., McMahon, S.J., Hyland, W.B., Muir, M.F., Trainor, C., Hounsell, A.R., O'Sullivan, J.M., Schettino, G., Currell, F.J., Hirst, D.G., and Prise, K.M., 2012, Cell type-dependent uptake, localization, and cytotoxicity of $1.9 \mathrm{~nm}$ gold nanoparticles, Int. J. Nanomed., 7, 2673-2685. 